\title{
Big Projects
}

As my presidential year comes to an end, I have been reflecting on what I have learned. I shall not bore you with a list of what has happened in these last 12 months, because I want to leave a single message for the future of materials research.

I have had broad interactions with government officials at all levels, and from many countries, in this busy, busy year. I am pleased to report that there is clearly a growing recognition that "Materials" is a legitimate and important field of research. The materials research community used to have such a low profile that it was all but invisible from the lofty viewpoint of Capitol Hill and other seats of government, but that has been partly corrected, although we still need to maintain and grow the level of awareness.

We are now poised, as a community, to move to the next level of governmental relations, but this is going to require some internal soul-searching, too. Physicists, chemists, astronomers, medical researchers, and others do not go to their governments to gain recognition for their fields: They go with a prioritized list of requests, generally for large-scale equipment. This is how huge projects like particle colliders, radio-telescope arrays, or human-genome projects are created. Not every physicist benefits from every particle collider, and not every astronomer will use the next big telescope, but as communities, they support these large initiatives on the understanding that big facilities ultimately benefit the field in many roundabout ways. They provide publicity that brings new people into the field, they provide centers of excellence where researchers gather and interact, and they push the research tools to new levels, with benefits for all. Even those who only work at the benchtop still benefit from improvements in detector capabilities developed for large colliders, for example. If you consider the Web a benefit, then remember that it was originally developed to share data among disparate computer systems at CERN.

Materials research traditionally casts itself in the role of "small science" and typically eschews leadership roles in large-scale facility development projects. There is often a sense that a big project

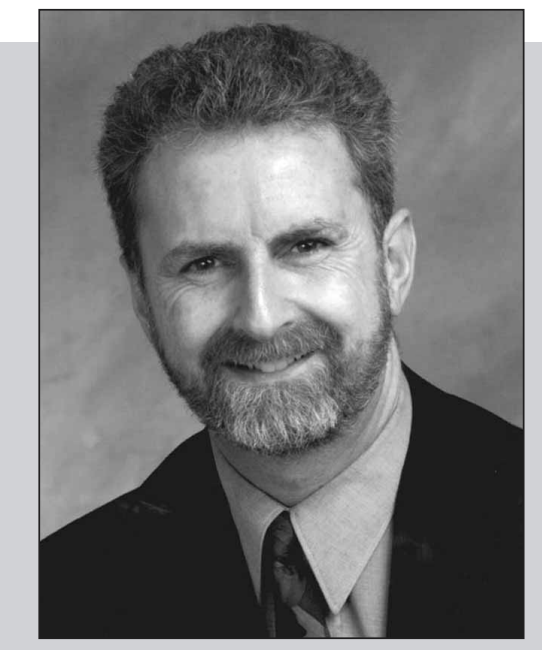

"We have the attention of the government, so now let's use it."

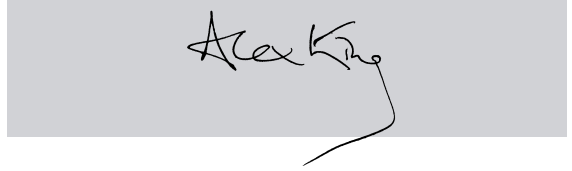

will siphon research funding away from small-scale researchers, but this perception is largely unfounded. We have always benefited from large-scale projects like synchrotron light sources and neutron sources, but these have largely been spearheaded by others. It is time for the materials community to come together and develop its own list of priorities for large-scale tools and capabilities, just as the astronomers and the high-energy physicists do-we have the attention of the government, so now let's use it.

The materials community in the United States suffers from a significant disadvantage in presenting its agenda to the government, because it does not speak with a single voice, the way that the American Physical Society (APS) speaks for physics, or the American Chemical Society (ACS) speaks for chemistry. It is not that we have competing agendas among the various materials societies; there is simply no "secretariat" that is entrusted by the whole community with developing the agenda for research tool development. Let me suggest that we create such a group from the leadership of the various materials societies and have it meet once or twice per year, on neutral ground under the sponsorship of the National Materials Advisory Board and/or the Committee on Solid-State Sciences, to set some priorities for large-scale materials research. This group might call for the building of single facilities, the creation of dispersed networks, or other mechanisms not yet dreamed of, to tackle problems that we cannot solve in our individual laboratories. We might expect that greater public awareness of materials science would also follow from some well-publicized projects.

Because it is hard to start such a process, and initial agendas will only develop over about a year, I am also suggesting that we look at some current opportunities as means to raise the profile of materials research, broadly. Among these, building aberration-corrected electron microscopes is only one timely example. Not everyone will benefit directly from sub-angstrom resolution, but designing these instruments will enhance contrast and sensitivity for all future generations of transmission electron microscopes (TEMs), enabling more quantitative spectroscopy and imaging. The development project will also increase the flexibility to include increasingly complicated in situ observation capabilities in future TEMs. I believe that the entire materials community should support the transmission electron achromatic microscope (TEAM) project proposed by the Department of Energy's National ElectronBeam Microcharacterization Centers to build a set of these instruments for use by all materials researchers (access Web site http:/ / ncem.lbl.gov/team.htm for details). We will all benefit in the long run.

I hope that the materials community will create a process by which projects of this type are intelligently prioritized by its leading members and placed visibly on the governmental radar screen. We need to take the lead in these decisions, for ourselves, rather than continuing to work with whatever capabilities happen to fall to hand.

Alex KING 2002 MRS President 